\title{
Elementary visual hallucinations, blindness, and headache in idiopathic occipital epilepsy: differentiation from migraine
}

\author{
C P Panayiotopoulos
}

\begin{abstract}
This is a qualitative and chronological analysis of ictal and postictal symptoms, frequency of seizures, family history, response to treatment, and prognosis in nine patients with idiopathic occipital epilepsy and visual seizures. Ictal elementary visual hallucinations are stereotyped for each patient, usually lasting for seconds. They consist of mainly multiple, bright coloured, small circular spots, circles, or balls. Mostly, they appear in a temporal hemifield often moving contralaterally or in the centre where they may be flashing. They may multiply and increase in size in the course of the seizure and may progress to other non-visual occipital seizure symptoms and more rarely to extraoccipital manifestations and convulsions. Blindness occurs usually from the beginning and postictal headache, often indistinguishable from migraine, is common. It is concluded that elementary visual hallucinations in occipital seizures are entirely different from visual aura of migraine when individual elements of colour, shape, size, location, movement, speed of development, duration, and progress are synthesised together. Postictal headache does not show preference for those with a family history of migraine. Most of the patients are misdiagnosed as having migraine with aura, basilar migraine, acephalgic migraine, or migralepsy simply because physicians are not properly informed of differential diagnostic criteria. As a result, treatment may be delayed for years. Response to carbamazepine is excellent and seizures may remit.

(F Neurol Neurosurg Psychiatry 1999;66:536-540)
\end{abstract}

Keywords: occipital seizures; migraine aura; elementary visual hallucinations; ictal blindness; postictal headache

Correspondence to:

Dr C P Panayiotopoulos, St Thomas' Hospital, London SE1 7EH, UK. Telephone 00441719228221 ; fax 0044 1719228263.

Received 7 May and in revised form

2 October 1998

Accepted 16 October 1998 also fundamental symptoms often with the same sequence of events in occipital seizures. ${ }^{1-9}$

This is a systematic prospective qualitative study of the characteristics of elementary visual hallucinations, blindness, and headache in idiopathic occipital epilepsy.

\section{Methods}

These are detailed elsewhere. ${ }^{9}{ }^{10}$ Patients with occipital seizures were prospectively evaluated and followed up from 1973. Nine patients with idiopathic occipital epilepsy with visual hallucinations (IOEVH) had:

(a) Incontrovertible clinical evidence of occipital seizures with or without secondarily generalisation.

(b) Normal physical, neurological, and mental states and high resolution MRI.

They all had detailed interviews, seven completed a purposely designed questionnaire, ${ }^{9}$ and eight provided drawings of their visual hallucinations.

\section{Results}

PREVALENCE

Of 1360 patients with epilepsies $63(4.6 \%)$ had occipital seizures and these were $25.4 \%$ definite (nine patients) or possible (seven patients) non-photosensitive IOEVH, 38.1\% early onset benign childhood occipital seizures, $27 \%$ symptomatic occipital epilepsy, and $9.5 \%$ idiopathic photosensitive occipital epilepsy. Sex, age, and other chronological data are provided in the table.

\section{ELEMENTARY VISUAL HALLUCINATIONS}

In all patients elementary visual hallucinations were the first and often the only ictal symptom.

\section{Colour, shape, and size}

All patients described coloured visual hallucinations, which were multicoloured in six, monochromatic in two, and dichromatic in one (figure). Bright red, yellow, blue, and green seemed to predominate. Shapes were circular, spots, circles, or balls in all but one, who described "shades of purple". In three patients additional coloured squares, triangles, and rectangular shapes in each were experienced together with the circular patterns that predominated. Individual elements of the visual 


\begin{tabular}{|c|c|c|c|c|c|c|c|c|c|c|c|}
\hline $\begin{array}{l}\text { Patient } \\
\text { No/sex }\end{array}$ & $\begin{array}{l}\text { Age at } \\
\text { last follow } \\
\text { up }(y)\end{array}$ & $\begin{array}{l}\text { Age at } \\
\text { onset } \\
\text { (y) }\end{array}$ & $\begin{array}{l}\text { Age at } \\
\text { last } \\
\text { seizure } \\
\text { (y) }\end{array}$ & $\begin{array}{l}\text { Duration of } \\
\text { epilepsy }(y)\end{array}$ & $\begin{array}{l}\text { Free of } \\
\text { seizures } \\
(y)\end{array}$ & $\begin{array}{l}\text { Frequency of } \\
\text { seizures }\end{array}$ & $\begin{array}{l}\text { Postictal } \\
\text { headache }\end{array}$ & $\begin{array}{l}\text { Family } \\
\text { history }\end{array}$ & $\begin{array}{l}\text { Anti-epileptic } \\
\text { drugs }\end{array}$ & $\begin{array}{l}\text { Seizures with } \\
A E D\end{array}$ & $\begin{array}{l}\text { Age at drug } \\
\text { withdrawal } \\
\text { (y) }\end{array}$ \\
\hline $1 / \mathrm{M}$ & 30 & 11 & 23 & 12 & 7 & Weekly & Severe & M & Barbiturate & 5 & 24 \\
\hline $2 / \mathrm{F}$ & 22 & 9 & 15 & 6 & 7 & Daily & Moderate & - & CBZP & 0 & 20 \\
\hline $3 / \mathrm{M}$ & 17 & 10 & 11 & 1 & 6 & Weekly & - & - & CBZP & 0 & 14 \\
\hline $4 / \mathrm{M}$ & 16 & 8 & 16 & 8 & 0 & Weekly & Severe & - & CBZP & Few VS & Continues \\
\hline $5 / M$ & 14 & 7 & 12 & 5 & 2 & Daily & - & M-E & CBZP & Few VS & Continues \\
\hline $6 / \mathrm{F}$ & 24 & 12 & 20 & 8 & 4 & Monthly & Severe & M-E & SV-CBZP & 0 after CBZP & Continues \\
\hline $7 / \mathrm{M}$ & 17 & 14 & 17 & 3 & 0 & Daily & Severe & M?-E? & CBZP & 0 & Continues \\
\hline $8 / \mathrm{M}$ & 21 & 12 & 21 & 9 & 0 & Daily & Severe & - & SV-CBZP & 0 after CBZP & Continues \\
\hline $9 / M$ & 25 & 25 & 25 & 0.5 & 0 & 4 in all & Severe & - & CBZP & Unknown & Continues \\
\hline Mean & 20.7 & 12.0 & 17.8 & 5.8 & 2.9 & & & & & & \\
\hline SD & 5.1 & 5.3 & 4.8 & 3.8 & 3.1 & & & & & & \\
\hline Median & 21 & 11 & 17 & 6 & 2 & & & & & & \\
\hline
\end{tabular}

$\mathrm{M}=$ Migraine; $\mathrm{E}=$ spilepsy; $\mathrm{CBZP}=$ carbamazepine; $\mathrm{SV}=$ sodium valproate; $\mathrm{VS}=$ visual seizures; $\mathrm{AED}=$ antiepileptic medication; ?=doubtful.

hallucinations were multiple (tens or hundreds) in seven and 2-4 in the other two. Their size varied from "spots" to, rarely, the size of a coin.

\section{Location}

Their location at onset was unilateral in six, appearing in the periphery of the left (four) or right temporal hemifield and central or of undefined localisation in three patients.

\section{Movement}

Horizontal movement towards the other side was a consistent finding in three patients that all had unilateral visual hallucinations. They were flashing in four with two of them having central visual hallucinations. Spinning visual hallucinations were described by one patient and rotating hallucinations in another.

Vision

Ictally, vision was obscured only in the area occupied by the visual hallucinations. Only one patient had a " $10 \%$ reduction of visual awareness before the onset of visual hallucinations" and this often could be the only ictal symptom, lasting for 1-2 seconds.

Duration

Most elementary visual hallucinations lasted for 5-30 seconds, rarely 1 minute. They could last up to 3 minutes in three patients and 10 minutes in another one. Two patients later had solitary or rare visual seizure lasting 15-20 minutes without other non-visual ictal symptoms. Usually, elementary visual hallucinations were longer before secondarily generalisation.

The components of visual hallucinations increased in numbers, size, or both with progress of seizure, particularly before other non-visual ictal symptoms.

Frequency and circadian distribution

Visual seizures usually occurred daily (table) and were diurnal in all but patient 6 , who would be wakened by them.

\section{Precipitating factors}

There were no obvious precipitating factors. One patient said that they were precipitated by exercise and heat, one by stress, one by hunger, one in darkness, one in looking at bright non-flickering lights, one with excess of alcohol.
Stereotypical appearance

The seizures were stereotyped in all aspects for every patient.

BLINDNESS AND HEMIANOPIA

Patients 1,3 , and 5 had rare episodic blindness lasting 2-3 minutes. This was usually infrequent and often occurred suddenly without other preceding occipital seizure symptoms. Hemianopia, ictal or postictal, is difficult to assess but was experienced by patients 3, 4, and 8 .

OTHER OCCIPITAL SEIZURE SYMPTOMS

The elementary visual hallucinations started and persisted, usually without other occipital seizure symptoms. Patients 3 and 8 also had illusions of eye movements. Patients 7 and 8 had eyelid fluttering or repetitive eyelid closures after the visual hallucinations when consciousness was impaired, progressing to generalised convulsions. Two patients had ipsilateral deviation of the eyes and head.

\section{COMPLEX VISUAL HALLUCINATIONS}

Only patient 3 in the progress of his elementary visual hallucinations saw "large objects, probably people, which I cannot identify".

PROGRESS OF VISUAL SEIZURES TO OTHER

NON-VISUAL MANIFESTATIONS

Visual seizures rarely progressed to other ictal manifestations. The pattern of progression varied significantly among the patients although it was usually stereotyped for each patient. Patient 1 had two seizures with dysphasia and slight confusion and one nocturnal secondary generalised tonic clonic seizures (GTCS). Also, he may have had two motor partial seizures. ${ }^{9}$ Patient 2 had only two ipsilateral motor partial seizures and four nocturnal GTCS. Patient 3 had four brief episodes of falls with loss of consciousness without convulsions that were unrelated to visual seizures. Visual hallucinations progressed to ipsilateral deviation of eyes and head with clonic hemiconvulsions on only three occasions in patient 3 . Patient 5 had two to three episodes with blindness, visual hallucinations, spinning around, and loss of muscular tone with a fall. Patient 6 had less than 12 GTCS secondary to visual seizures. In patient 7 , visual seizures exceptionally progressed to impairment of conscious- 
A
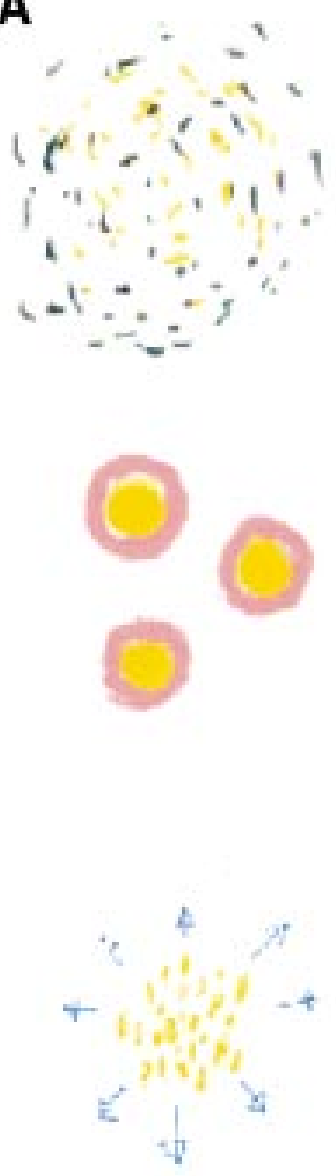
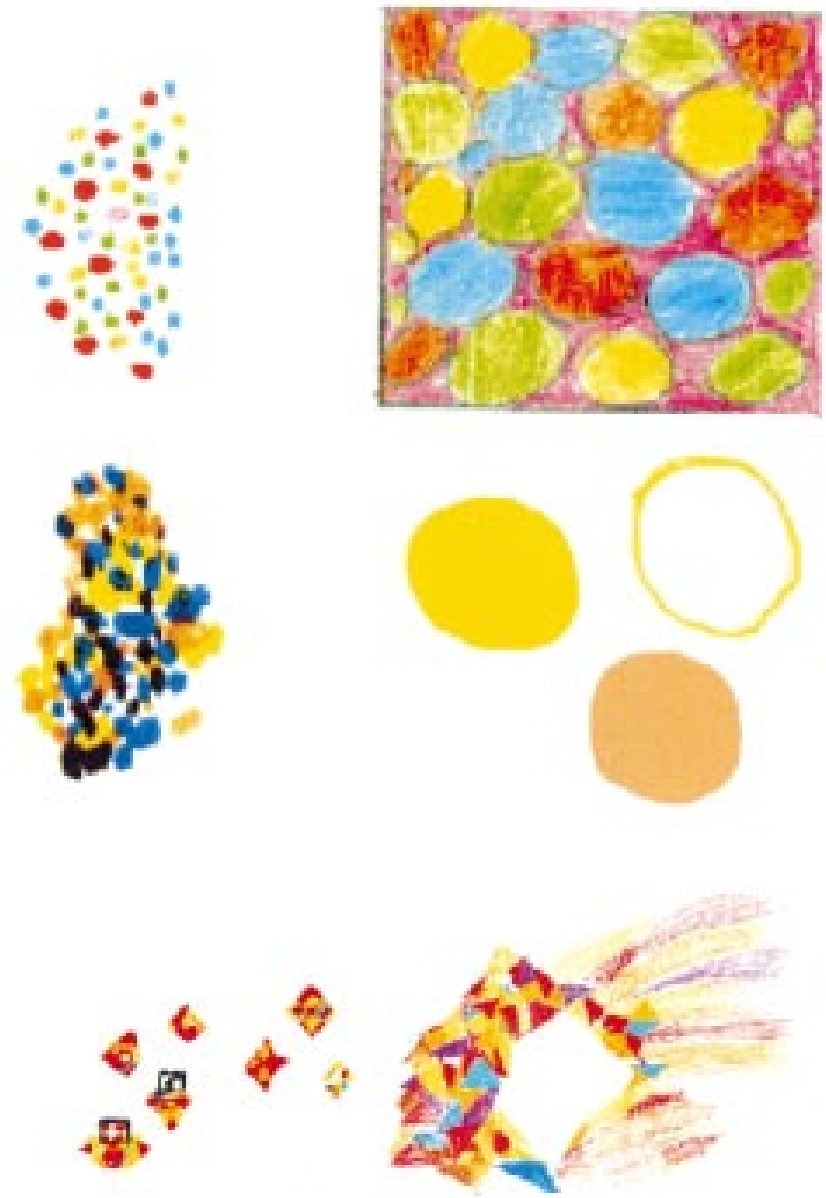

B

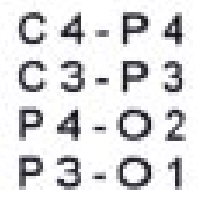

P 3-O 1

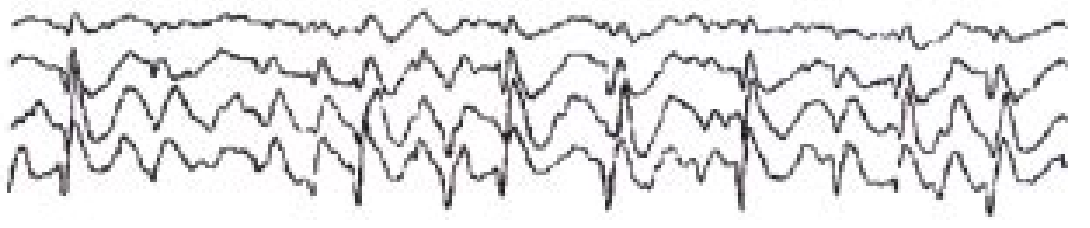

$1 \mathrm{~s}$

$1100 \mu \mathrm{V}$

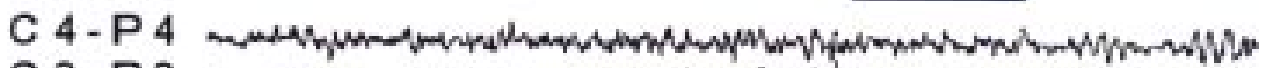

C $3-P 3$

P 4-O2

P 3-O1

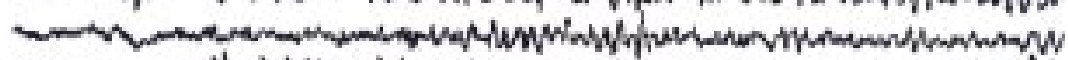

mom

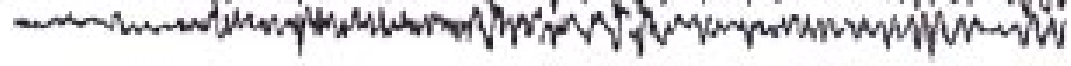

$1 \mathrm{~s}$

$100 \mu \mathrm{V}$

(A) Elementary visual hallucinations as perceived and drawn by eight of the nine patients with IOEVH. First and second row from left to right: the illustrations of patients 1 to 6 are consecutively presented. Third row from left to right: the illustrations of patient 7 (left) and 8 at onset (middle) and just before progressing to loss of consciousness and GTCS (right). (B) From video-EEG recordings. First row: high amplitude occipital paroxysms from video-EEG of patient 3. They were immediately activated by closing the eyes and persisted as long as the eyes were closed. Opening the eyes immediately eliminated the occipital paroxysms for as long as the eyes were opened. The occipital paroxysms were similarly activated in conditions of elimination of fixation and central vision (darkness, vision through goggles covered with semitransparent tape) and inhibited in conditions that these were preserved (fixation off sensitivity). Second row: low amplitude, occipital fast rhythms intermixed with spikes from video-EEG of patient 6 . These occurred immediately after closing the eyes. They did not persist during the remaining period that the eyes were closed. Contrary to the occipital paroxysms of patient 3 , they were eliminated in darkness and the patient also had time locked occipital spikes induced by intermittent photic stimulation.

ness, eyelid flickering, and GTCS. Patient 8 woke up on 12 occasions with a sense of fear and violently spinning around for $2-3$ seconds, followed by his habitual visual hallucination that ended up with "an explosion of colours that flicker in the centre of my eyes like flash 
camera" for another 10 seconds (figure). Subsequently, he became unresponsive; his eyes stared and dilated followed by slow repetitive eye closures for 1 minute before secondary GTCS. Patient 9 had only four late onset visual seizures, three progressing to GTCS. Only once between the phase of visual hallucinations and GTCS he had "double vision with the right side moving up and the left down".

POSTICTAL SYMPTOMS OF VISUAL SEIZURES: HEADACHE AND OTHER MIGRAINE-LIKE FEATURES This refers to postictal symptoms after visual seizures alone and not to postconvulsion headache and vomiting (table). Six patients had severe headache that was mainly bilateral, rarely unilateral, pounding or throbbing, and often associated with nausea and vomiting. In one patient it was persistently located behind the eyes.

The headache would start immediately but usually within 3-15 minutes after the end of visual hallucinations. Duration was 30 minutes to 3 hours, exceptionally 12 hours. The longer the duration of visual seizures, the longer and more severe the headache was. However, even simple, elementary visual hallucinations of less than 1 minute duration could trigger severe headache in most patients.

MIGRAINE

None of the patients had the typical visual aura of migraine described by Russell and Olesen ${ }^{11}$ or any other type of visual hallucinations except for their habitual ones. Two patients had frequent headaches that were never associated with visual hallucinations.

FAMILY HISTORY OF MIGRAINE AND EPILEPSY (TABLE)

There was no other family member having the same type of seizures as these patients.

Postictal headache occurred in three of four patients with and four of five without a family history of migraine (table).

ELECTROENCEPHALOGRAPHIC FINDINGS

All patients had awake and sleep EEG. Only three patients (Nos 1-3, table) had occipital paroxysms. Additionally, patient 6 had fast occipital spikes immediately after closing her eyes and photically induced occipital spikes locked to the flash stimulus. ${ }^{9}$ Patient 7 had brief, abortive generalised discharges of small spikes and slow waves of higher amplitude in the anterior regions.

DIAGNOSIS, TREATMENT, AND OUTCOME (TABLE) All but two patients were initially misdiagnosed as migraine with aura, acephalgic migraine, and basilar migraine and unsuccessfully treated with antimigraine medication. Of all patients who received carbamazepine, all seizures, even the minor visual ones, stopped completely. Three patients remained free of seizures after withdrawal of treatment (table). Patient 6 was not controlled on sodium valproate alone but all seizures ceased when carbamazepine was added at the age of 18 . For the past 2 years she has been on carbamazepine monotherapy and is free of any type of minor or major seizures.

\section{Discussion}

The reason for strictly limiting this study to idiopathic occipital epilepsy is for a better comparison with migraine that is also idiopathic.

\section{ARE THESE SEIZURES OR MIGRAINE?}

The elementary visual hallucinations detailed cannot be anything else but visual seizures. They are entirely different from migraine visual aura in their clustering of colour, shape, size, location, movement, duration, and development. Epileptic elementary visual hallucinations are mainly coloured, with circular patterns, have the same onset regarding localisation, and progress, they are often brief, lasting for seconds, develop fast and their individual components may multiply or move together to the contralateral side. They are mainly frequent, often daily, and sometimes accompany other occipital seizure symptoms ${ }^{9}$ such as eye and head deviation, illusions of eye movement, eyelid repetitive closures, or fluttering. ${ }^{679}$ Blindness that lasts longer and may occur from the beginning is not uncommon. ${ }^{6}{ }^{9}$ Postictal headache is frequent and often indistinguishable from migraine. ${ }^{59}$

Conversely, the visual aura of migraine with aura and acephalgic migraine starts with predominantly flickering achromatic or black and white, linear, and zigzag patterns in the centre of the visual field, gradually expanding over minutes towards the periphery of one hemifield and often leaves a scotoma. ${ }^{11}$ They rarely exhibit daily frequency. Less typical features of migraine visual aura and coloured patterns have been described ${ }^{12}$ but clustering of other symptoms as above betray their migraine nature. Non-visual epileptic occipital symptoms do not occur. Although possible, it is probably exceptional to progress to convulsions. ${ }^{13} 14$

I have recently extensively reviewed basilar migraine and concluded that reported associations with occipital epilepsy are probably erroneous. ${ }^{9}$ Basilar migraine is characterised by transient and fully reversible aura symptoms indicating focal dysfunction of the brain stem, the occipital lobes, or both, followed by headache. ${ }^{15-17}$ Common neurological symptoms of aura include visual symptoms of mainly bilateral blurring or blindness, dizziness, vertigo and tinnitus, ataxia, bilateral weakness, and dysaesthesia, diplopia, dysarthria, and decreased hearing. In only one of the reported cases "colourful displays" are mentioned. ${ }^{18}$ Aura symptoms develop gradually over 4 minutes and last for less than an hour. Impairment or loss of consciousness without convulsions may occur in $25 \%$ of patients between the aura and the headache phase. The attacks of basilar migraine are usually infrequent and over the years there is a tendency for them to cease or to be replaced by common varieties of migraine with or without aura. ${ }^{15}$

MIGRALEPSY VERSUS EPILEPSY-MIGRAINE Migralepsy, an old term deriving from migra(ine) and (epi)lepsy for "a seizure that may be a composite of symptoms encountered in 
epilepsy and migraine" 19 has been recently reintroduced. ${ }^{13}$ Intercalated seizures are to denote epileptic seizures occurring between the migrainous aura and the headache phase of migraine. ${ }^{14}$ There should be no reason that epileptic seizures, so vulnerable to extrinsic and intrinsic precipitating factors, could not be susceptible to cortical changes introduced by migraine. However, this is surprisingly so extremely rare that only a few case reports have been published despite the fact that migraine and epilepsy are among the commoner brain diseases. According to a recent review, ${ }^{9}$ most of these are genuine occipital seizures imitating migraine aura. ${ }^{9}$ For example, two of the three "migralepsy" patients of Lennox and Lennox ${ }^{19}$ seemed to have symptomatic and idiopathic occipital epilepsy with visual hallucinations.

None of the 1360 patients of the initial population of this report and none of the nine patients with IOEVH had any evidence of seizures developing from migraine aura although this was often the initial erroneous diagnosis. ${ }^{9}$ Conversely, postictal headache and other migraine-like symptoms occurred in these patients that make an epilepsy-migraine sequence a more realistic proposition.

BLINDNESS

Three of the nine patients had ictal blindness as the only seizure manifestation, rarely preceded by visual hallucinations or followed by other seizure manifestations and postictal headache and vomiting. Blindness is well documented in occipital epilepsy, ${ }^{6}{ }^{79}$ migraine with aura, ${ }^{11}$ and basilar migraine. ${ }^{15-18}$ Postictal scotoma, hemianopia, and blindness occur in all these diseases and they are not specific for any of them.

HEADACHE

Postictal headache was often indistinguishable from migraine headache associated with nausea and vomiting. It was equally common in those with or without a family history of migraine. Other similarities with migraine headache are that in some patients this started 3-15 minutes after the end of visual hallucinations and it was longer and more severe with visual seizures of longer duration. Similar postictal headache has been reported in symptomatic patients ${ }^{320}$ but is mainly emphasised in idiopathic occipital seizures. ${ }^{5}$ It may be that the seizure discharges in the occipital lobes trigger a genuine migraine headache through trigeminovascular or brain stem mechanisms. ${ }^{521}$

\section{Conclusion}

The quality and the chronological sequence of ictal elementary visual hallucinations are markedly different from the visual aura of migraine. The concept of migralepsy or of a migraine-epilepsy sequence needs revaluation based on accurate diagnosis. The emerging concept of occipital seizures triggering migrainous headache is more likely. More importantly, patients with daily visual seizures that may progress to convulsions merit a precise diagnosis and appropriate treatment, probably with carbamazepine. Visual seizures and migraine aura may imitate each other but their true identity cannot easily escape clinical scrutiny.

1 Panayiotopoulos CP. Elementary visual hallucinations in migraine and epilepsy. $\mathcal{F}$ Neurol Neurosurg Psychiatry 1994;57:1371-4

2 Panayiotopoulos CP, Ahmed Sharoqi I, Agathonikou A. Occipital seizures imitating migraine aura. $\mathcal{F} R$ Soc $M e d$ 1997;90:255-7

3 Russell WR, Whitty CWM. Studies in traumatic epilepsy 3. Visual fits. F Neurol Neurosurg Psychiatry 1955;18:79-96.

4 Ludwig BI, Marsan CA. Clinical ictal patterns in epileptic patients with occipital electroencephalographic foci. Neurology 1975;25:463-71

5 Gastaut H, Zifkin BG. Benign epilepsy of childhood with occipital spike and wave complexes. In: Andermann F, Lugaresi E, eds. Migraine and epilepsy. Boston: Butterworths, 1987:47-81.

6 Salanova V, Andermann F, Olivier A, et al. Occipital lobe epilepsy: electroclinical manifestations, electrocorticography, cortical stimulation and outcome in 42 patients treated between 1930 and 1991 . Surgery of occipital lobe epilepsy. Brain 1992;115:1655-80.

7 Williamson PD, Thadani VM, Darcey TM, et al. Occipital Williamson PD, Thadani VM, Darcey TM, et al. Occipital
lobe epilepsy: clinical characteristics, seizure spread patterns, and results of surgery. Ann Neurol 1992;31:3-13.

8 Sveinbjornsdottir S, Duncan JS. Parietal and occipital lobe epilepsy: a review. Epilepsia 1993;34:493-521.

9 Panayiotopoulos CP. Benign childhood partial seizures and related epileptic syndromes. London: John Libbey, 1999.

10 Panayiotopoulos CP. Benign childhood epilepsy with occipital paroxysms: a 15-year prospective study. Ann Neurol 1989;26:51-6.

11 Russell MB, Olesen J. A nosographic analysis of the migraine aura in a general population. Brain 1996;119: 355-61.

12 Shevell MI. Acephalgic migraines of childhood. Pediatr Neurol 1996;14:211-5.

13 Marks DA, Ehrenberg BL. Migraine-related seizures in adults with epilepsy, with EEG correlation. Neurology 2476-83.

14 Terzano MG, Parrino L, Pietrini V, et al. Migraine-epilepsy syndrome:intercalated seizures in benign occipital epilepsy. In: Andermann F, Beaumanoir A, Mira L, eds. Occipital seizures and epilepsies in children. London: John Libbey, 1993:93-9.

15 Bickerstaff ER. Basilar artery migraine. Lancet 1961;i:1517.

16 Bickerstaff ER. The basilar artery and the migraine-epilepsy syndrome. Proc R Soc Med 1962;55:167-9.

17 Sturzenegger $\mathrm{MH}$, Meienberg O. Basilar artery migraine: a follow-up study of 82 cases. Headache $1985 ; 25: 408-15$.

18 Swanson JW, Vick NA. Basilar artery migraine 12 patients, with an attack recorded electroencephalographically. Neurology 1978;28:782-6.

19 Lennox WG, Lennox MA. Epilepsy and related disorders. Boston: Little, Brown, 1960.

20 Schon F, Blau JN. Post-epileptic headache and migraine. $\mathcal{F}$ Neurol Neurosurg Psychiatry 1987;50:1148-52.

21 Welch KM. Pathogenesis of migraine. Semin Neurol 1997;17:335-41. 